The men concerned had received multiple injections of analgesics and antihistamines with consequent haematoma formation in the gluteal and lateral thigh musculature. With the exception of small volume injections during immunization, intramuscular therapy is usually unnecessary and always dangerous in patients with coagulation defects. The consequent haemorrhage not only causes pain and pressure on surrounding tissues, but may result in muscle fibrosis and permanent crippling.-I am, etc.,

Children's Department, Royal Victoria Infirmary

Peter Jones Newcastle upon 'Tyne

\section{Smallpox Vaccination}

SIR,-The recent outbreak of smallpox in Yugoslavia with several secondary cases in that country and one in Germany has moved the case of routine vaccination of infants for a review. I feel that Professor George Dick (17 July 1971, p. 163) and Lane et al. ${ }^{1}$ as well as Thomas $M$. Mack ${ }^{2}$ should give us more detailed information about the age of those children where primary vaccination gave such disastrous complications.

Experience from Sweden shows that primary vaccination performed at two months carries a rate of complications that is minimal down to the point of being virtually non-existent. At this age the babies are still to some extent protected against generalized vaccinia by passive immunity transferred from their mothers and they have very seldom developed any type of eczema. As the protection obtained at this age can be assumed to be of shorter duration because of interference from the maternal antibodies just mentioned than the protection conveyed by a vaccination performed later in life, in our schedule of immunizations children are recommended to be revaccinated against smallpox at an age of about 11 years. Most males are revaccinated on entering military service when about 20 , and our health authorities strongly recommend doctors to encourage travellers to be revaccinated before making international journeys even inside Europe, in order to keep up their level of immunity and the herd immunity. Risk groups-for example, staff at hospitals, police, and customs personnel, are revaccinated regularly every third year. At a meeting of the representatives of those responsible for the immunization policy in the Nordic states (Denmark, Finland, Norway, and Sweden; I am not sure whether Iceland was represented or not) recently it was concluded that nothing had occurred that might weaken the reasons for continued legislation on smallpox vaccination.

Of course complications from smallpox vaccination are seen, but they are not nearly as common or dangerous with these regularly repeated inoculations as the risk of an emergency vaccination of a contact with a history of 30 years or more without vaccination or revaccination. The sale of smallpox vaccine amounts to about one million doses yearly, and only about $10 \%$ of these are believed to be discarded. As the birth rate is $90000-100,000$ a year most doses are used for revaccination. A prerequisite is that contraindications wherever existing are discovered and accepted, but with proper use of vaccinia immunoglobulin even some of these cases may be protected, especially as many of these unfortunate patients are in greater need than others of journeys to sunny beaches.

The legislation on smallpox vaccination includes notification of complications. I do not feel that the recommendation for smallpox vaccination to be abandoned in U.K. and U.S.A. can be reversed, but I earnestly plead for continued vaccination so long as there is still no evidence of smallpox being eradicated from this earth nor from the freeze-boxes of virological laboratories.-I am, etc., Medical Faculty,
Royal University of Umeå,

LARS M. Hambraeus

Umeâ, Sweden

1 Lane, J. M., Millar, J. D., and Neff, J. M., 2 Annual Review of Medicine, 1971, 22, 251 . 1972, 125, 161 .

\section{Episodic Blindness}

SIR,-To the very thorough leading article on episodic blindness (15 April, p. 122) should like to add reference to a recently reported further series of 12 unusual cases. While some of the cases suggest atypical late-life migrainous accompaniments without headache others may represent an obscure new syndrome that is probably benign.-I am, etc.,

\section{Miller Fisher}

Massachusetts General Hospital,
Boston, Massachusetts, U.S.A.

Fisher, C. M., Clinical Neurosurgery, 1971, 18,

\section{Respiratory Stimulants}

SIR,-While generally agreeing with the sentiments expressed by your expert contributors in relation to the uses of respiratory stimulants (27 May, p. 522) I was disappointed to see no mention of xanthine derivatives in this context.

The continuous intravenous infusion of aminophylline at a rate of about $500 \mathrm{mg}$ every six hours will provide useful increases in minute ventilation. As well as "buying time" for other treatment to become effective, this will commonly correct the element of acute hypercapnia associated with acute or chronic respiratory failure and remove the necessity for mechanical ventilation.

The other actions of aminophyllinebronchodilator, diuretic, pulmonary, and coronary vasodilator-would seem to provide additional reasons for its more widespread use in the management of acute respiratory failure.-I am, etc., Royal Mellourne Hospital,

Michael C. F. PaIN

\section{Coronary Bypass Grafting}

SIR,- - Excessive enthusiasm has so far been avoided in Britain"-from your leading article on coronary artery bypass grafting (10 June, p. 603). ". . . our results compare closely to those of others, showing that $89 \%$ of patients are improved by the operation"-from an article on the same subject (p. 644), which showed that only $84 \%$ of patients electively submitted to the operation actually survived it.

No, Sir, that's not enthusiasm, that's British phlegm-it was even quoted in The
Times Science Report (Monday, 12 June). -I am, etc.,

Newcastle upon Tyne

ROGER HOLE

\section{Tax Relief for G.P.s}

SIR,-Dr. J. F. Rickards (10 June, p. 658) implies that doctors generally have difficulty in understanding the intricacies of the N.H.S. superannuation scheme and the proposed new Inland Revenue changes with regard to private pension schemes. He does not think one general practitioner in a hundred could understand the recent B.M.A article on the subject. I doubt whether this is so.

There is certainly nothing mysterious or difficult to understand about the N.H.S. superannuation scheme. It is only necessary to understand one fact about this scheme to realize how disadvantageous it is to doctors, and that is the absence of any money in the fund. The doctor does not contribute $6 \%$ of his gross salary or income. He receives $94 \%$ of his income instead of $100 \%$, the difference of $6 \%$, plus the employers contribution of $8 \%$ (imaginary) is credited to a "notional" (imaginary) fund which, in the first seven years of the scheme, was credited with no interest whatsoever, and since then has only been credited with a ridiculously small amount of interest. In the case of private schemes, of course, the money is real and the contributions are invested, so it is not surprising to hear from $\mathrm{Dr}$. Richards that the pension and the lump sum from a private scheme are so much better for a given amount of contributions. One is not surprised to meet doctors, including consultants, who having retired from various branches of the National Health Service, are still working after retirement. Even if the value of money remained static the scheme would still be a poor one, and it is even more so with the present inflation.

In the Ministry's explanatory leaflet on the N.H.S. superannuation scheme the first words state that the scheme is compulsory, and this is of course the snag. One cannot opt out and contribute to a private scheme instead. If the proposed alteration in the tax relief for general practitioners in respect of contributions to a private pension scheme is effected the situation will be even worse than it is at present. The only mysterious aspect of this whole business to me is the ready acceptance of this scheme in the first place by those who negotiated on our behalf, and the failure to modify it in anything but the most minor degree since the scheme was put into operation 24 years ago. Now it appears that the British Medical Association even has to negotiate to retain tax concessions which have been allowed for a number of years. - I am, etc.,

Marple, Ches.

W. J. Stanley

\section{Slimming and Efficiency}

SIR,-Industry has recently undergone a slimming process with increased efficiency. Could not the same be tried with the hordes of nursing, lay, and other administrators in the Health Service? -I am, etc.,

J. Elwes Duffield 